\title{
PARTIDOS DE OPOSIÇÃO NOS ESTADOS: o ambiente da competição na arena eleitoral ${ }^{1}$
}

\author{
Gabriela da Silva Tarouco*
}

\begin{abstract}
O artigo propõe uma operacionalização do conceito de oposição baseada nas posturas assumidas publicamente pelos partidos e testa sua aplicação em uma análise comparada da arena eleitoral entre quatro estados brasileiros. $\mathrm{O}$ ambiente da competição entre situação e oposição em Minas Gerais, Pernambuco, São Paulo e Rio Grande do Sul é analisado através de uma série de indicadores empíricos nas eleições de 2002 e 2006. A análise mostra grandes variações na competitividade das oposições, nas estratégias de coligação e na lealdade dos eleitores aos partidos, a despeito dos efeitos institucionais não variarem. Tais resultados sugerem que fatores locais específicos devem ser mobilizados para explicar o comportamento dos partidos de oposição no nível subnacional.

PALAVRAS-CHAVE: oposições, competição eleitoral, arena eleitoral, partidos, esfera subnacional.
\end{abstract}

\section{INTRODUÇÃO}

A possibilidade de existência de oposições livres é, pelo menos desde Dahl (1966, 1971), um requisito incontestável da democracia e, por essa razão, foi objeto central nos estudos sobre transições e consolidação nos países da chamada terceira onda de democratização (Huntington, 1994). Concluída a transição, a liberdade de contestação deixa de ser uma variável a chamar as atenções dos analistas e se torna um dado do quadro institucional. A agenda de pesquisa sobre oposições se volta, então, para o comportamento das oposições e suas relações com os governos e com os resultados de políticas públicas.

\footnotetext{
${ }^{1}$ Este artigo contém alguns dos resultados da pesquisa "O lugar das oposições na política subnacional" desenvolvido em cooperacão entre a UFMG, UNIFESP e UFPE, com financiamento do CNPq e da FAPEMIG, tendo sido discutido em eventos internos pelos participantes do projeto, aos quais agradeço pelos comentários. Agradeço também aos pareceristas anônimos do Caderno CRH pelas preciosas sugestões.

* Doutora em Ciência Política pelo IUPERJ. Professora do Departamento de Ciência Política da Universidade Federal de Pernambuco. Integra o Grupo de Pesquisa "Partidos, Eleições e Comportamento Político”, desenvolvendo pesquisas na área de Partidos Políticos e Governança Eleitoral.

Av. Acadêmico Hélio Ramos s/n. Cidade Universitária Cep: 50670-900. Recife-Pernambuco-Brasil gabrielat@uol.com.br
}

Um dos objetivos buscados por todos os partidos é influenciar as políticas públicas de acordo com suas preferências (ou plataformas). ${ }^{2}$ A formulação da agenda de políticas públicas não é um jogo de soma zero como na arena eleitoral, em que os cargos ganhos por um partido não o são por outro. No processo de composição da agenda pública, os partidos de oposição também exercem uma influência decisiva, levantando questões para debate e apontando problemas que não podem ser ignorados pelo governo (Kingdon, 2003). A efetividade da oposição se manifesta, entre outros aspectos, quando os partidos de oposição conseguem influenciar as políticas públicas, seja na aprovação de projetos, seja na oferta eleitoral bem sucedida de um programa alternativo (Altman; Pérez-Liñan, 1999).

Apesar da indiscutível relevância do objeto, o estudo empírico das oposições ainda envolve uma série de desafios. O primeiro deles é a própria definição: a tarefa de elaboração conceitual parece estar inconclusa na literatura, provavel-

${ }^{2}$ Os outros são: cargos, rendimento, votos (Müller; Strom, 1999). 
mente porque não é tão simples como parece. $\mathrm{O}$ segundo desafio é a operacionalização do conceito: a correta identificação das observações que refletem o conceito, ou seja, a identificação dos atores que se situam no campo da oposição não é, como pode parecer à primeira vista, trivial.

Este artigo pretende contribuir para o enfrentamento desses desafios, propondo uma definição e testando sua operacionalização em uma análise do ambiente de competição eleitoral nos estados de Minas Gerais, Pernambuco, Rio Grande do Sul e São Paulo, nas eleições de 2002 e 2006. ${ }^{3}$ Com isso, a proposta é elaborar uma avaliação comparativa da competitividade na arena eleitoral que possa subsidiar a análise das estratégias das oposições em outras arenas, notadamente a legislativa e a judicial.

O texto a seguir está dividido em três seções. A primeira trata da questão conceitual, oferece critérios de operacionalização e os aplica aos casos selecionados. A segunda reúne uma série de indicadores empíricos com o objetivo de compor o quadro em que se dá a competição eleitoral. Por último, as considerações finais trazem a sistematização da análise e algumas conclusões.

\section{PARTIDOS DE OPOSIÇÃO: definição e operacionalização}

Uma definição preliminar de oposição que pode servir de ponto de partida para a pesquisa empírica é a definição residual, segundo a qual oposição seria "tudo que não seja governo". Esse é um conceito do tipo mínimo, ou seja, com requisitos mínimos que facilitama identificação de casos empíricos. A facilidade de operacionalização é evidente e torna a sua utilização muito tentadora.

${ }^{3}$ A seleção desses estados para análise não obedece a critérios de amostragem e, por isso, as conclusões não são generalizáveis. Quaisquer outros estados poderiam ter cumprido, da mesma forma, a função de casos exemplares onde observar as oposições subnacionais. A rigor, trata-se de estados em que variam significativamente os outros aspectos desenvolvidos no projeto do qual resulta esta análise: (a) ocorrência de alternância no governo estadual no período em análise; (b) características dos subsistemas partidários estaduais; (c) características organizacionais das Assembleias Legislativas; (d) tamanho e características organizacionais do Poder Executivo estadual (Inácio, 2008).
Entretanto, a variedade de atores que não são governo e que, portanto, deveriam ser classificados como oposição, traz a desvantagem típica dos conceitos mínimos: ao englobarem objetos muito diversificados, ajudam pouco na sua compreensão. ${ }^{4}$ No caso do estudo das oposições, o risco da adoção do conceito mínimo é negligenciar diferenças que podem ser cruciais no entendimento do comportamento dos atores no ambiente de competição política.

Frequentemente, a renúncia à simplicidade traz ganhos em precisão. Esse é exatamente o caso da definição do conceito de oposições. Fazer referência "às oposições" de maneira genérica implica o pressuposto de uma uniformidade artificial que pode comprometer os resultados de análises relacionais. Ignorar que o espaço político "fora do governo" inclui posicionamentos distintos afeta as conclusões que mobilizem a variável oposição como explicativa, e também aquelas que a tratem como variável dependente.

Assim, o primeiro objetivo deste trabalho é propor uma definição alternativa para o objeto "oposições", ainda que com consequências pouco convenientes para a sua operacionalização. Dado que a oposição não pode ser tratada como homogênea, a análise de partidos de oposição é bem mais promissora. ${ }^{5}$ Dessa forma, partido de oposição seria aquele que assume publicamente uma posição de disputa em relação ao governo. Esse critério exclui da categoria "oposição" aqueles partidos que, mesmo não participando do bloco do governo, não o confrontam.

Assim, teríamos uma variável categórica, e a classificação dos partidos produziria três tipos:

I. Partido de oposição: aquele que se posiciona publicamente como partido de oposição, seja se apresentando em eleições como

4 Trata-se do trade-off entre thin e thik concepts: conceitos "leves", ou seja, com menos requisitos, vão mais longe, abarcando e explicando mais ocorrências empíricas. Conceitos que contêm mais elementos, por outro lado, dizem mais sobre o objeto e são menos frequentemente observados na realidade. Um exemplo é o debate em torno da definição "minimalista" de democracia (Gerring, 2001).

${ }^{5}$ Partidos políticos são unidades de análise mais adequadas, apesar de também não poderem, a rigor, ser tomados como atores unitários. 
desafiante do governo, seja se declarando como opositor ao governo na legislatura.

II. Partido governista ou de situação: aquele partido que abriga o governante, ou que assume publicamente apoio ao governo ou à candidatura que o governo apoia, seja participando da coligação eleitoral que abriga o partido do mandatário, seja participando do governo com cargos ou declarando participar da base de apoio ao governo na legislatura.

III. Partido indefinido: categoria residual que abriga qualquer partido que não se enquadre nas demais categorias.

É importante chamar a atenção para a importância conferida à autodeclaração como indicador do status do partido. O critério da autodeclaração dos partidos tem sido adotado em pesquisas sobre posicionamento ideológico, ênfases programáticas e apoio parlamentar a reformas, e está sustentado no debate teórico e metodológico contemporâneo sobre preferências partidárias. A opção por esse critério se baseia no pressuposto de que o que um partido declara publicamente sobre si mesmo pode ser considerado válido como medida de suas preferências. ${ }^{6}$

As consequências da utilização do conceito proposto incluem:

a) um mesmo partido pode mudar de status entre o momento eleitoral e a legislatura, e também durante uma mesma legislatura;

b) a definição do status do partido depende do governo que é a referência (estadual ou nacional);

c) essa defiQuadro 1 - Protocolo de classifica
de oposição eleitoral $^{7}$

\begin{tabular}{|c|c|c|c|c|c|}
\hline $\begin{array}{l}\text { 1) } \\
\text { É o partido do } \\
\text { governador? }\end{array}$ & $\begin{array}{l}\quad \text { 2) } \\
\text { Lançou } \\
\text { candidato a } \\
\text { governador? }\end{array}$ & $\begin{array}{l}\quad \text { 3) } \\
\text { Se lançou, } \\
\text { participou da } \\
\text { coligação do } \\
\text { partido do } \\
\text { governador? }\end{array}$ & $\begin{array}{l}\quad 4 \text { ) } \\
\text { Se não lançou, } \\
\text { participou da } \\
\text { coligação do } \\
\text { partido do } \\
\text { governador? }\end{array}$ & $\begin{array}{l}\quad \text { 5) } \\
\text { Se não lançou candidato } \\
\text { nem participou da } \\
\text { coligação do partido do } \\
\text { governador, participou de } \\
\text { coligação de partido } \\
\text { desafiante? }\end{array}$ & Bloco \\
\hline Sim & - & - & - & - & Situação \\
\hline Não & Sim & Não & - & - & Oposição \\
\hline Não & Sim & Sim & - & - & Situação \\
\hline Não & Não & - & Não & Sim & Oposição \\
\hline Não & Não & - & Sim & - & Situação \\
\hline Não & Não & - & Não & Não & Indefinido \\
\hline
\end{tabular}
nição trata como residuais os partidos que não

${ }^{6}$ Tais posicionamentos públicos já foram analisados através de surveys com lideranças (Power, 1998; Power; Zucco Junior, 2011) e através de análise de documentos programáticos (Tarouco, 2011). concorrem em uma determinada eleição nem declaram apoio a outros competidores e também aqueles partidos que, na legislatura, declarem-se "independentes" durante o tempo em que durarem essas condições;

d) o exercício de influência sobre a agenda de políticas públicas não afeta a distinção entre partidos de oposição e de situação.

A operacionalização do conceito seguiria etapas específicas quer se esteja tratando da arena eleitoral, quer da arena legislativa.

Assim, um partido será classificado como oposição eleitoral quando, participando do processo eleitoral, não abriga o mandatário, nem participa de coligação com o partido do mandatário, e lança candidato ou participa de coligação que lança candidato ao governo. Um partido será classificado como de situação quando, participando do processo eleitoral, abriga o mandatário ou participa de coligação com o partido do mandatário. No Brasil, os dados necessários a respeito da composição das coligações eleitorais são facilmente acessíveis eletronicamente através do site do Tribunal Superior Eleitoral (TSE). O Quadro 1 abaixo ilustra as etapas da operacionalização na arena eleitoral: 
Os partidos que competiram nas eleições de 2002 e 2006, nos estados de Minas Gerais, Pernambuco, Rio Grande do Sul e São Paulo, foram classificados segundo os critérios definidos acima como pode ser verificado nos Quadros 2 e 3 a seguir.

O Quadro 2 e o Quadro 3 permitem observar que a quantidade de partidos indefinidos diminuiu, de 2002 para 2006, em quase todos os estados, exceto São Paulo.

\section{INDICADORES ELEITORAIS: análise do ambiente da competição}

O ambiente em que se dá a disputa eleitoral pode ser mais competitivo ou menos, conforme a quantidade de partidos, a dispersão ou concentração do apoio eleitoral entre eles e o histórico do desempenho dos partidos em eleições anteriores. Tais aspectos conjunturais afetam as estratégias de campanha e as decisões acerca das coligações eleitorais.

Quadro 2 - Classificação dos partidos por bloco nas eleições de 2002

\begin{tabular}{|c|c|c|c|c|}
\hline \multirow{2}{*}{ Partido } & \multicolumn{4}{|c|}{ Estado } \\
\hline & $\mathrm{MG}$ & $\mathrm{PE}$ & $\mathrm{RS}$ & $\mathrm{SP}$ \\
\hline PAN & Oposição & Oposição & Indefinido & Oposição \\
\hline PC do B & Oposição & Oposição & Situação & Oposição \\
\hline PCB & Oposição & Oposição & Situação & Oposição \\
\hline PCO & Oposição & Oposição & Oposição & Oposição \\
\hline PDT & Indefinido & Oposição & Indefinido & Oposição \\
\hline PFL & Oposição & Situação & Oposição & Situação \\
\hline PGT & Indefinido & Oposição & Indefinido & Oposição \\
\hline PHS & Oposição & Indefinido & Oposição & Oposição \\
\hline PL & Oposição & Oposição & Oposição & Oposição \\
\hline PMDB & Situação & Situação & Oposição & Oposição \\
\hline $\mathrm{PMN}$ & Oposição & Oposição & Situação & Indefinido \\
\hline PPB & Oposição & Situação & Oposição & Oposição \\
\hline PPS & Indefinido & Indefinido & Oposição & Oposição \\
\hline PRONA & - & - & Oposição & Oposição \\
\hline PRP & Indefinido & Oposição & - & Oposição \\
\hline PRTB & Oposição & Oposição & - & Oposição \\
\hline PSB & Oposição & Oposição & Oposição & Oposição \\
\hline PSC & Indefinido & Indefinido & Oposição & Oposição \\
\hline PSD & Indefinido & Indefinido & - & Situação \\
\hline PSDB & Oposição & Situação & Oposição & Situação \\
\hline PSDC & Oposição & Indefinido & - & Oposição \\
\hline PSL & Oposição & Oposição & Oposição & Oposição \\
\hline PST & Indefinido & Oposição & - & Oposição \\
\hline PSTU & Oposição & Oposição & Oposição & Oposição \\
\hline $\mathrm{PT}$ & Oposição & Oposição & Situação & Oposição \\
\hline PT do B & Indefinido & Oposição & Oposição & Oposição \\
\hline РТВ & Indefinido & Oposição & Indefinido & Oposição \\
\hline PTC & Indefinido & Oposição & - & Oposição \\
\hline PTN & Oposição & Indefinido & Oposição & Oposição \\
\hline PV & Oposição & Indefinido & Oposição & Oposição \\
\hline
\end{tabular}

Fonte: Tribunal Superior Eleitoral. Elaboração da autora. 
Gabriela da Silva Tarouco

Quadro 3 - Classificação dos partidos por bloco nas eleições de 2006

\begin{tabular}{|c|c|c|c|c|}
\hline \multirow{2}{*}{ Partido } & \multicolumn{4}{|c|}{ Estado } \\
\hline & MG & $\mathrm{PE}$ & RS & SP \\
\hline PAN & Situação & Oposição & Oposição & Oposição \\
\hline PC do B & Oposição & Oposição & Oposição & Oposição \\
\hline PCB & Indefinido & Oposição & Oposição & Oposição \\
\hline PCO & Oposição & Oposição & Oposição & Oposição \\
\hline PDT & Indefinido & Oposição & Oposição & Oposição \\
\hline PFL & Situação & Situação & Oposição & Situação \\
\hline PHS & Situação & Situação & Oposição & Oposição \\
\hline PL & Situação & Oposição & Oposição & Oposição \\
\hline PMDB & Oposição & Situação & Situação & Oposição \\
\hline PMN & Indefinido & Oposição & Situação & Indefinido \\
\hline PPB & Situação & Oposição & Oposição & Oposição \\
\hline PPS & Situação & Situação & Oposição & Situação \\
\hline PRP & Oposição & Indefinido & - & Oposição \\
\hline PRONA & Oposição & Oposição & Oposição & Indefinido \\
\hline PRB & Oposição & Oposição & - & Oposição \\
\hline PRTB & Oposição & Indefinido & Oposição & Indefinido \\
\hline PSB & Situação & Oposição & Oposição & Oposição \\
\hline PSC & Situação & Oposição & Oposição & Oposição \\
\hline PSDB & Situação & Situação & Oposição & Situação \\
\hline PSDC & Oposição & Oposição & Oposição & Oposição \\
\hline PSL & - & Indefinido & Indefinido & Oposição \\
\hline PSOL & Oposição & Oposição & Oposição & Oposição \\
\hline PSTU & Oposição & Oposição & Oposição & Oposição \\
\hline PT & Oposição & Oposição & Oposição & Oposição \\
\hline РTB & Situação & Oposição & Situação & Situação \\
\hline PT do B & Oposição & Indefinido & Oposição & Oposição \\
\hline PTC & Oposição & Indefinido & Oposição & Oposição \\
\hline PTN & Oposição & Situação & - & Oposição \\
\hline PV & Indefinido & Indefinido & Oposição & Oposição \\
\hline
\end{tabular}

Fonte: Tribunal Superior Eleitoral. Elaboração da autora.

Há, na literatura, uma série de indicadores que refletem as condições da competição eleitoral. Nesta seção, serão analisados os seguintes índices: volatilidade eleitoral, número efetivo de partidos, índice de oposição efetiva e índice de competitividade. Além disso, as coligações eleitorais serão submetidas à análise de rede para comparar as configurações estaduais distintas.

\section{Volatilidade eleitoral}

O apoio eleitoral que um partido obtém varia no tempo. Quanto maior for essa variação, maior a incerteza a respeito do desempenho futuro, pois ela indica menos estabilidade das preferências dos eleitores. O índice de volatilidade eleitoral (Pedersen, 1980) mede essa variação em termos agregados, para o conjunto de partidos. 
Altos índices de volatilidade eleitoral costumam aparecer, em grande parte das análises, associados à baixa institucionalização dos sistemas partidários nas democracias não consolidadas, mas podem também indicar a avaliação retrospectiva do eleitor em relação aos partidos no governo e na oposição. ${ }^{8}$ É nesse sentido que o índice de volatilidade será utilizado nesta seção.

Calculado pela totalização das variações entre uma eleição e outra, na votação obtida pelos partidos, ${ }^{9}$ o índice de volatilidade eleitoral varia de 0 (quando a proporção de votos recebida em uma eleição é igual à anterior, para todos os partidos) até 100 (caso em que todos os eleitores mudaram seu voto) e pode ser expresso em termos de porcentagem. Segundo diversos analistas, a volatilidade eleitoral no sistema partidário brasileiro é alta em comparação com os índices de outros países, e isso se explica em parte pela facilidade e frequência com que surgem novos partidos. ${ }^{10}$

A volatilidade entre as eleições de 2002 e 2006 foi calculada para os estados de Minas Gerais, Pernambuco, Rio Grande do Sul e São Paulo e pode ser verificada na Tabela 1 a seguir.

Tabela 1 - Volatilidade eleitoral total, 2002-2006

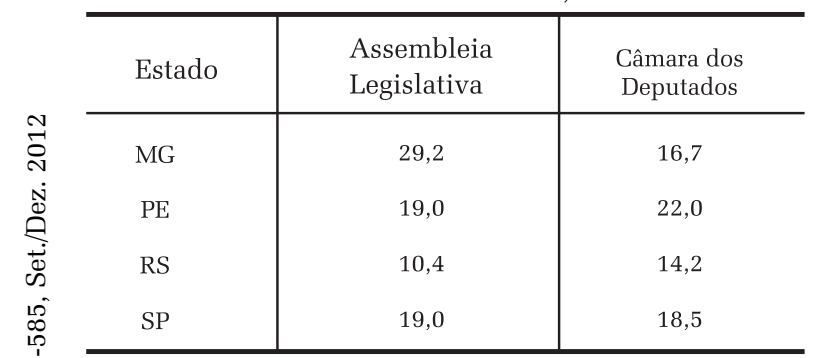

Fonte: Tribunal Superior Eleitoral. Elaboração da autora

Outros estudos de volatilidade eleitoral nos estados brasileiros trazem valores diferentes, provavelmente por adotarem critérios diferentes na determinação dos partidos sucessores

${ }^{8}$ Para uma discussão sobre a relação entre volatilidade e institucionalização (Tarouco,2010).

${ }^{9}$ Volatilidade Eleitoral Total $=\left(\sum \Delta P i V\right) / 2$, em que $\Delta \mathrm{PiV}$ representa a variação, de uma eleição para outra, na proporção de votos do partido $i$.

${ }^{10}$ Para uma discussão sobre as interpretações da volatilidade eleitoral brasileira, ver Peres (2005).
(Peres, 2005; Braga, 2006; Bohn; Paiva, 2009). Quando partidos se fundem ou se dividem no intervalo entre as duas eleições, cabe ao analista estabelecer em que condições um partido pode ou não ser considerado sucessor de outro para o cálculo da variação das proporções de votos. Neste trabalho, são adotados os critérios de Bartolini e Mair (1990), e consideradas as seguintes continuidades:

a) em abril de 2003, o PST e o PGT se incorporaram ao PL: o PL, em 2006, foi considerado sucessor da soma dos três partidos de 2002.

b) em dezembro de 2002, o PSD se incorporou ao PTB: o PTB, em 2006, foi considerado sucessor da soma dos dois partidos de 2002.

c) o PRB, em 2006, foi considerado partido novo, sem votação em 2002 (seu antecessor, o PMR, só foi criado em 2005).

d) em 2005, o PSOL foi criado a partir de uma dissidência do PT: o PT, em 2002, foi considerado antecessor da soma dos dois partidos de 2006.

Os resultados da volatilidade eleitoral acima sugerem que, na escolha dos deputados estaduais, o eleitorado de Minas Gerais foi o que apresentou a maior mudança entre partidos e o do Rio Grande do Sul, a menor. Já no que diz respeito à votação para deputados federais, foi em Pernambuco que houve mais mudança de votos entre partidos e no Rio Grande de Sul, menos. A comparação parece indicar que os eleitores gaúchos estão mais fortemente ligados a partidos do que os demais, o que poderia conferir maior previsibilidade aos resultados das eleições no Rio Grande do Sul.

A volatilidade eleitoral também pode ser calculada entre partidos de um determinado bloco e entre blocos de partidos. A proposta de Bartolini e Mair (1990), ao formularem os índices de volatilidade intrabloco e volatilidade de bloco, era avaliar como a mudança de apoio eleitoral se dava entre partidos semelhantes. A volatilidade de bloco e a volatilidade intrablocos seriam partes que compõem a volatilidade total. Assim, tais índices consideram conjuntos de par- 
tidos, como de esquerda e de direita, religiosos e laicos. Segundo Nicolau (2004), esse tratamento poderia ser aplicado também aos blocos oposição e situação.

Entretanto, oposição e situação são blocos de natureza muito distinta dos demais. Partidos, em geral, são de esquerda ou de direita, são religiosos ou laicos, mas estão - temporariamente - na oposição ou na situação. ${ }^{11}$ Assim, uma alta volatilidade entre os blocos oposição e situação indica que os partidos mudaram de bloco (perderam ou ganharam eleições), e não que os eleitores mudaram para um partido de outro bloco. $O$ índice de volatilidade eleitoral interblocos calculado para os blocos oposição e situação deve, portanto, ser interpretado antes como indicador de avaliação retrospectiva do governo, e não como indicador de lealdade dos eleitores a partidos. A Tabela 2 a seguir traz esses dados para os quatro estados.

Tabela 2 - Volatilidade interblocos: oposição, situação e indefinidos, 2002-2006

\begin{tabular}{l|c|c|c}
\hline Estado & $\begin{array}{c}\text { Assembleia } \\
\text { Legislativa }\end{array}$ & $\begin{array}{c}\text { Câmara dos } \\
\text { Deputados }\end{array}$ & $\begin{array}{c}\text { Sucesso eleitoral do governo (principais } \\
\text { partidos permanecem no mesmo bloco) }\end{array}$ \\
\hline MG & 39,7 & 40,5 & Não \\
PE & 19,6 & 20,8 & Sim \\
RS & 23,0 & 20,0 & Não \\
SP & 20,5 & 14,6 & Sim \\
\hline
\end{tabular}

Fonte: Tribunal Superior Eleitoral. Elaboração da autora

Os valores da Tabela 2 acima são maiores que os da volatilidade total, contrariando o princípio de composição do índice, exatamente devido à peculiaridade dos blocos: os partidos podem mudar do bloco oposição para o bloco situação ou vice-versa de uma eleição para outra inclusive mantendo semelhante proporção de votos - devido ao sucesso ou fracasso das estratégias de coligação.

Segundo Bartolini e Mair (1990), a volatilidade interblocos é uma maneira de refinar a análise sobre instabilidade, pois, calculada pela variação do desempenho entre o conjunto de partidos de esquerda e o conjunto dos partidos de

${ }^{11}$ Pressupondo um contexto de liberdades democráticas. direita, por exemplo, não seria afetada pela mudança dos eleitores entre partidos do mesmo bloco ideológico. Uma mudança desse tipo não poderia ser equiparada à mudança entre um partido de um bloco ideológico para outro oposto, o que, aí sim, indicaria instabilidade.

A volatilidade interblocos pressupõe, assim, que cada partido pertença a um determinado bloco de forma constante e, por isso, ela não tem o mesmo significado quando aplicada aos blocos oposição e situação cuja composição é, por definição, ao menos em democracias, variável. Ainda de acordo com Bartolini e Mair (1990), no cálculo da volatilidade interblocos, partidos que compartilham de alguma propriedade em comum são agrupados e tratados de forma unitária. A variação de desempenho a ser considerada no cálculo será entre duas eleições consecutivas dessa mesma unidade agregada. Tratar oposição e situação como blocos só faria sentido se os partidos que compõem cada um permanecessem unidos, apenas se transferindo, todos, de um bloco para outro, quando as eleições resultam em alternância de governo. ${ }^{12}$ No caso do Brasil, é comum a composição das coligações variar de modo a incluir partidos que anteriormente eram adversários e, assim, oposição e situação deixam de ser blocos passíveis de tratamento agregado para serem produto de composições flutuantes.

O valor mais alto da volatilidade interblocos - justamente naqueles estados em que o governo perdeu e tornou-se oposição (e vice-versa) - parece confirmar que aí o índice não está medindo a mudança dos eleitores entre partidos de blocos diferentes, mas sim a capacidade de os partidos conservarem seus eleitores depois de mudarem de bloco.

${ }^{12}$ Esse seria o caso se, por exemplo, esquerda e direita em blocos se alternassem no governo. Mas não é o caso quando partidos de esquerda ora estão coligados com outros de esquerda, ora com partidos de direita. 
Mais uma vez, o melhor exemplo é o Rio Grande do Sul: a volatilidade interblocos é bem maior que a volatilidade partidária total, porque o PT, que era situação em 2002 e oposição em 2006, obteve uma porcentagem de votos muito próxima nas duas eleições. ${ }^{13}$

\section{Número efetivo de partidos (NEP)}

A quantidade de competidores é um aspecto crucial da arena eleitoral. Quanto mais partidos, mais candidatos, mais disperso o apoio eleitoral e mais complexas as decisões a respeito das estratégias de coligação. A fragmentação partidária será aqui analisada com recurso ao índice proposto por Laakso e Taagepera (1979), que mede a dispersão ou concentração de partidos levando em conta, além da sua quantidade nominal, o seu peso relativo em termos de desempenho eleitoral. ${ }^{14} \mathrm{O}$ índice NEP pode ser interpretado como uma contagem de partidos relevantes, apesar de, por admitir números fracionários, não poder ser utilizado para determinar quais são esses partidos relevantes.

O Número Efetivo de Partidos foi calculado para as eleições de 2002 e 2006 para os estados

Tabela 3 - Número Efetivo de Partidos eleitorais,

\begin{tabular}{l|c|c|c}
\hline \multicolumn{2}{|c|}{2002 e 2006 } & $\begin{array}{c}\text { Assembléia } \\
\text { Legislativa }\end{array}$ & $\begin{array}{c}\text { Câmara dos } \\
\text { Deputados }\end{array}$ \\
\hline MG & 2002 & 10,1 & 8,6 \\
& 2006 & 10,1 & 10,4 \\
PE & 2002 & 11,9 & 7,9 \\
& 2006 & 12,2 & 9,6 \\
RS & 2002 & 7,5 & 6,8 \\
& 2006 & 8,3 & 8,5 \\
SP & 2002 & 8,3 & 8,0 \\
& 2006 & 7,9 & 8,9 \\
\hline
\end{tabular}

Fonte: Tribunal Superior Eleitoral. Elaboração da autora

${ }^{13}$ A votação do PT caiu menos de 5 pontos percentuais de 2002 para 2006, tanto para a Assembleia Legislativa quanto para a Câmara dos Deputados.

${ }^{14} \mathrm{NEP}=1 / \sum p^{2} i$ em que p é a proporção de votos obtida pelo partido $i$. O Número Efetivo de Partidos também pode ser calculado com a proporção de cadeiras legislativas obtidas, com a finalidade de medir a fragmentação parlamentar. de Minas Gerais, Pernambuco, Rio Grande do Sul e São Paulo e pode ser verificado na Tabela 3.

Os valores da Tabela 3 acima mostram que a fragmentação partidária, que já era alta em 2002, aumentou em 2006, além de ser geralmente maior nas eleições para deputado estadual. Uma configuração como essa gera incentivos para que os partidos façam amplas coligações eleitorais, como pode ser verificado na Tabela 4 a seguir.

Tabela 4 - Partidos na disputa para governador,

\begin{tabular}{|c|c|c|c|c|c|}
\hline \multirow{2}{*}{ Eleição } & \multirow{2}{*}{ Partidos } & \multicolumn{4}{|c|}{ Estado } \\
\hline & & MG & $\mathrm{PE}$ & RS & SP \\
\hline \multirow{3}{*}{2002} & Isolados & 5 & 5 & 9 & 9 \\
\hline & Coligados & 14 & 17 & 11 & 20 \\
\hline & Total & 19 & 22 & 20 & 29 \\
\hline \multirow{3}{*}{2006} & Isolados & 1 & 4 & 6 & 8 \\
\hline & Coligados & 23 & 19 & 19 & 18 \\
\hline & Total & 24 & 23 & 25 & 26 \\
\hline
\end{tabular}

Fonte: Tribunal Superior Eleitoral. Elaboração da autora.

Nos dados acima, é possível observar uma redução, de 2002 para 2006, do número de partidos que competem isolados e um aumento do número de partidos que competem coligados.

\section{Análise de rede das coligações}

A técnica de análise de redes é uma ferramenta originalmente desenvolvida para descrever redes sociais, enfatizando mais as relações do que os atores (pessoas). As relações estabelecidas no interior de um grupo social podem assumir formas muito complexas, que a análise de rede ajuda a desvendar.

No caso das coligações eleitorais, não se trata exatamente de uma rede social, mas o recurso à análise de rede se justifica pelas vantagens que a visualização gráfica oferece. Os Gráfi$\cos 1$ a 8 a seguir ilustram as configurações das coligações eleitorais nos estados de Minas Gerais, Pernambuco, Rio Grande do Sul e São Paulo nas eleições de 2002 e 2006.

Entre os diversos recursos que a análise 
Gráfico 1 - Coligações para governador em MG, 2002
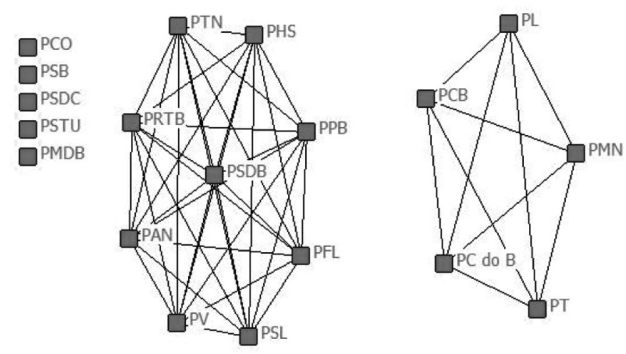

Gráfico 3 - Coligaçóes para governador em RS, 2002
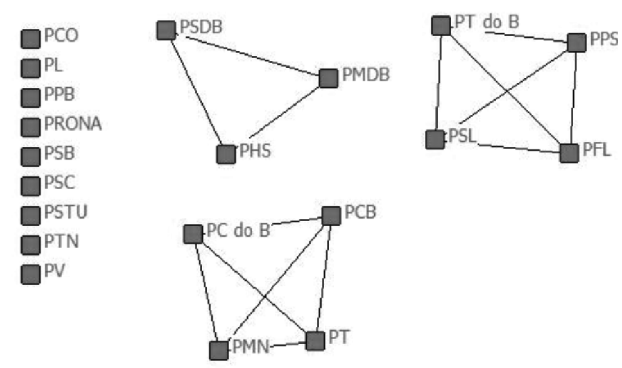

Gráfico 5 - Coligações para governador em MG, 2006

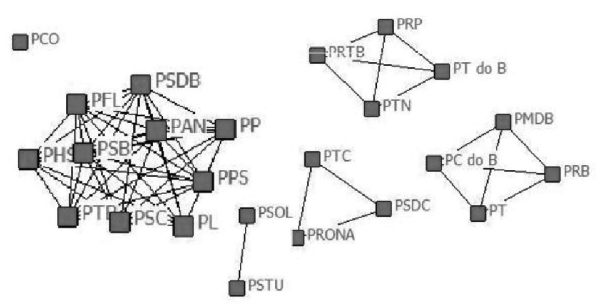

Gráfico 7 - Coligações para governador em RS, 2006

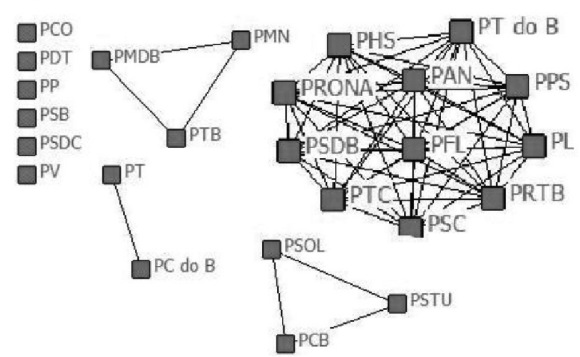

Fonte: Tribunal Superior Eleitoral. Elaboração da autora.
Gráfico 2 - Coligações para governador em PE, 2002
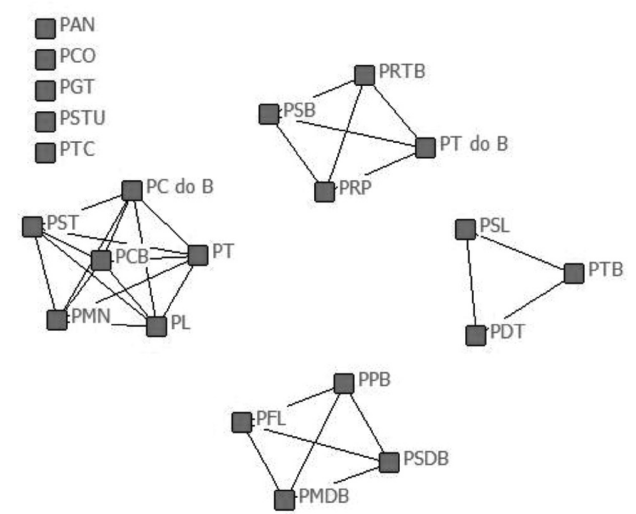

Gráfico 4 - Coligações para governador em SP, 2002
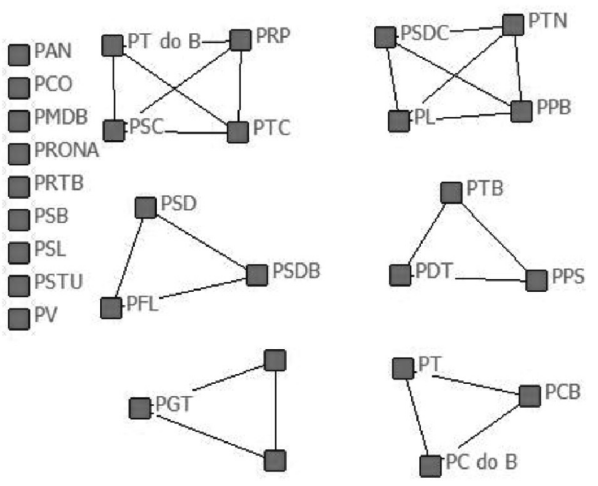

Gráfico 6 - Coligações para governador em PE, 2006
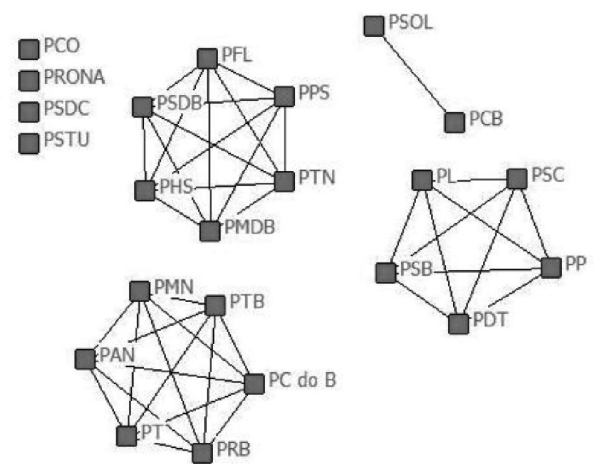

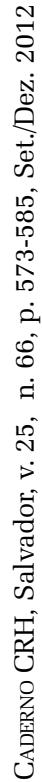

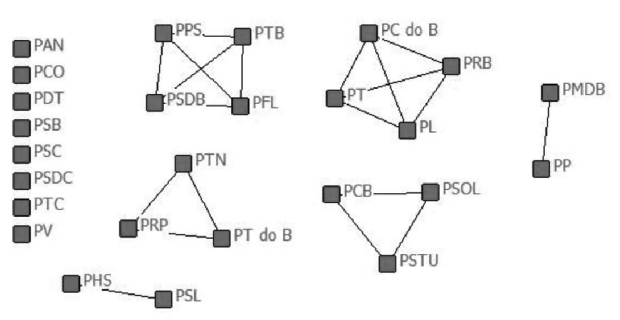


de redes disponibiliza, o índice de densidade da rede pode interessar para a análise das coligações eleitorais. A densidade de uma rede mede a proporção de relações efetivamente estabelecidas em relação ao total de relações possíveis (Hanneman; Mark, 2005).

$\mathrm{Na}$ arena eleitoral, o índice de densidade poderia ser interpretado como o grau em que os competidores estão dispostos a se coligarem, ou seja, até que ponto eles julgam vantajoso negociar preferências formando uma coligação em troca de aumentar suas chances eleitorais. Quanto maior a densidade, maior a proporção de partidos que recorrem à estratégia da coligação. A densidade corresponderia a 0 se todos os partidos competissem isoladamente e a 1 se todos participassem da mesma coligação. A Tabela 5 a seguir mostra o resultado do cálculo da densidade para as configurações dos quatro estados, em cada uma das eleições.

Tabela 5 - Índice de Densidade nas eleições para governador, em 2002 e 2006

\begin{tabular}{l|c|c}
\multirow{2}{*}{ Estado } & \multicolumn{2}{|c}{ Eovernador, em 2002 e 2006 } \\
\cline { 2 - 3 } & 2002 & 2006 \\
\hline $\mathrm{MG}$ & 0.2690 & 0.2210 \\
$\mathrm{PE}$ & 0.1299 & 0.1621 \\
$\mathrm{RS}$ & 0.0789 & 0.2077 \\
$\mathrm{SP}$ & 0.0591 & 0.0615 \\
\hline
\end{tabular}

\نnte: Tribunal Superior Eleitoral. Elaboração da autora

\section{Índice de oposição efetiva e índice de competitividade}

A efetividade da oposição é uma medida fundamental para avaliar o ambiente competitivo. Altman e Pérez-Liñan (1999) propõem um conjunto de índices que comparam a proporção de cadeiras legislativas da oposição com a da situação. O Índice de Oposição Efetiva (IOE) não se resume à razão entre as proporções, mas penaliza a fragmentação, por ser esse um aspecto decisivo na efetividade da oposição. Assim, o índice corresponde à razão entre um indicador ponderado da potência da oposição e um indicador ponderado da potência do governo. ${ }^{15}$ Para fins deste artigo, será adotada uma adaptação, substituindo-se a porcentagem de cadeiras pela porcentagem de votos. Assim, o Índice de Oposição Efetiva aplicado à arena eleitoral é calculado para os estados de Minas Gerais, Pernambuco, Rio Grande do Sul e São Paulo para as eleições de 2002 e 2006 e pode ser verificado na Tabela 6.

O IOE tende a zero quando o governo obtém a totalidade dos votos e a 1 quando a oposição e o governo empatam, podendo atingir valores superiores a 1 quando a oposição tem um desempenho eleitoral bem maior, ou quando os votos dados ao governo são fragmentados em muitos partidos (Altman; Pérez-Liñan, 1999).

\footnotetext{
${ }^{15} \mathrm{IOE}=\mathrm{O} / \mathrm{G}$ onde $\mathrm{O}$ reflete a potência da oposição e $\mathrm{G}$ reflete a potência do governo; $\mathrm{O}=\sum \mathrm{o}^{2} \mathrm{i} / \mathrm{\Sigma}$ oi onde oi corresponde à porcentagem de cadeiras (ou votos, nesse caso) do partido opositor i; $G=\sum g^{2} i / \sum$ gi onde gi corresponde à porcentagem de cadeiras (ou votos, nesse caso) do partido governista i (Altman; Pérez-Liñan, 1999). A penalização da fragmentação ocorre no cálculo de cada indicador de potência ( $\mathrm{O}$ e G), que vai compor o Índice, quando se eleva ao quadrado, no numerador $\left(\mathrm{o}^{2}\right.$ e $\left.\mathrm{g}^{2}\right)$, as porcentagens de votos obtidas. Números menores que 1, elevados ao quadrado, ficam ainda menores; números maiores que 1 por sua vez ficam ainda maiores. Assim, por exemplo, a porcentagem de votos obtida pelo PCO nas eleições para deputado federal em Minas Gerais em 2006 foi 0,047, que, elevada ao quadrado resulta em 0,002; a porcentagem de votos obtida pelo PT na mesma eleição foi de 16,544 , que ao quadrado chega a 273,71. Assim, uma eventual profusão de partidos de oposição com desempenho muito pequeno não aumentaria artificialmente a potência da oposição, o mesmo valendo
} para o governo. 


\begin{tabular}{l|c|c|c} 
Tabela 6 & $\begin{array}{c}\text { Índice de Oposição Efetiva nas eleições } \\
\text { de 2002 e 2006 }\end{array}$ \\
\hline \multirow{2}{*}{ Estado } & Eleição & $\begin{array}{c}\text { Assembléia } \\
\text { Legislativa }\end{array}$ & $\begin{array}{c}\text { Câmara dos } \\
\text { Deputados }\end{array}$ \\
\hline MG & 2002 & 0,996 & 1,145 \\
& 2006 & 0,768 & 1,414 \\
PE & 2002 & 0,583 & 0,832 \\
& 2006 & 0,686 & 0,935 \\
RS & 2002 & 0,519 & 0,515 \\
& 2006 & 0,852 & 0,780 \\
SP & 2002 & 0,713 & 0,810 \\
& 2006 & 0,583 & 0,614 \\
\hline
\end{tabular}

Fonte: Tribunal Superior Eleitoral. Elaboração da autora

Os dados acima apontam que a oposição é geralmente menos efetiva na disputa pelos cargos de Deputado Estadual do que na disputa por cadeiras na Câmara de Deputados, com exceção do Rio Grande do Sul. Também na Câmara de Deputados, além disso, a efetividade da oposição aumentou em 2006, quando comparada aos índices de 2002, em quase todos os estados analisados, exceto São Paulo. Na disputa para as Assembleias Legislativas, por sua vez, o Índice de Oposição Efetiva aumentou de 2002 para 2006 em dois estados (PE e RS) e diminuiu nos outros dois (MG e SP).

A partir dos mesmos indicadores preliminares acima, Altman e Pérez-Liñan (1999) propõem também um Índice de Competitividade, para mensurar o equilíbrio entre governo e oposição. ${ }^{16} \mathrm{O}$ Índice $\mathrm{C}$ tende a 0 sempre que um dos lados (governo ou oposição) tende a controlar a legislatura inteira, e a 1 quando as diferenças entre governo e oposição são mínimas. Novamente, o índice será adaptado para a arena eleitoral, substituindo-se a proporção de cadeiras pela proporção de votos. Calculado para os estados de Minas Gerais, Pernambuco, Rio Grande do Sul e São Paulo para as eleições de 2002 e 2006, o índice varia conforme a Tabela 7 .

Os dados mostram um claro equilíbrio entre oposição e governo, com o índice muito próximo de 1 em todos os estados. Tanto a eleição de

${ }^{16} \mathrm{C}=1-|(\mathrm{O}-\mathrm{G}) / 100|$
Tabela 7 - Índice de Competitividade nas eleições de 2002 e 2006

\begin{tabular}{l|c|c|c}
\hline \multirow{2}{*}{ Estado } & Eleição & $\begin{array}{c}\text { Assembléia } \\
\text { Legislativa }\end{array}$ & $\begin{array}{c}\text { Câmara dos } \\
\text { Deputados }\end{array}$ \\
\hline MG & 2002 & 0,9995 & 0,9827 \\
& 2006 & 0,9733 & 0,9636 \\
PE & 2002 & 0,9506 & 0,9759 \\
& 2006 & 0,9659 & 0,9928 \\
RS & 2002 & 0,9001 & 0,8849 \\
& 2006 & 0,9799 & 0,9691 \\
SP & 2002 & 0,9560 & 0,9722 \\
& 2006 & 0,9304 & 0,9421 \\
\hline
\end{tabular}

Fonte: Tribunal Superior Eleitoral. Elaboração da autora

2002 quanto a eleição de 2006 foram altamente competitivas.

\section{CONSIDERAÇÕES FINAIS}

Oposição é uma variável importante em diversas áreas da ciência política: em estudos sobre as relações entre executivo e legislativo, sobre impacto dos partidos em políticas públicas, sobre consolidação e institucionalização da própria democracia. A classificação de partidos como opositores ao governo gera efeitos nos resultados de tais pesquisas e, portanto, deve ser muito cuidadosa.

No presente artigo, foi apresentada uma proposta de definição e operacionalização baseada nas posturas assumidas publicamente pelos partidos. Além disso, foi desenvolvida uma aplicação dessa proposta em uma análise da competição eleitoral em casos selecionados. Os resultados, mesmo que não sejam conclusivos, apontam para a pertinência dos critérios propostos e indicam um futuro promissor para a agenda de pesquisas a respeito das oposições no Brasil.

O ambiente de competição eleitoral é determinado por uma série de fatores que, como vimos, variam entre os estados de Minas Gerais, Pernambuco, Rio Grande do Sul e São Paulo. A produção de explicações para essa variação exigiria uma pesquisa mais ampla, mas, sendo o quadro institucional constante, já que a legisla- 
ção eleitoral é a mesma em todo o território nacional, já podemos afirmar que não se podem atribuir as diferenças observadas aos incentivos institucionais.

Os casos selecionados, ainda que não possam ser tratados como uma amostra representativa para generalizações nacionais, podem ser considerados exemplares de realidades políticas específicas, com tradições, cultura e história política distintas. ${ }^{17}$ Parece razoável associar a fatores dessa natureza resultados como a lealdade dos eleitores aos partidos no Rio Grande do Sul, a amplitude das coligações em Minas Gerais, a alta volatilidade eleitoral em Pernambuco, ou, ainda, a profusão de pequenas coligações eleitorais em São Paulo.

A configuração das disputas eleitorais em 2002 e 2006 e as estratégias de coligação adotadas pelos partidos provavelmente afetam as estratégias dos partidos de oposição na arena legislativa e na arena judicial. A continuidade e a ampliação de estudos como este permitirá estabelecer a lógica dessas relações e compreender melhor o comportamento das oposições nos estados no Brasil.

Texto recebido em 04 de dezembro de 2011 Aceito em 20 de junho de 2012

\section{REFERÊNCIAS}

ALTMAN, David; PÉREZ-LIÑAN, Aníbal. Mas allá de la poliarquia: una aproximación a la calidad de las democracias. Revista Uruguaya de Ciencia Política, Montevideo, $\mathrm{n}$ 11, p. 85-105,1999. Disponível em: www.fcs.edu.uy archivos/20071102011032.pdf. Acesso em: 2 jan. 2013.

BARTOLINI, Stefano; MAIR, Peter. Identity, competition, and electoral availability. Cambridge: Cambridge University Press, 1990.

BOHN, Simone; PAIVA, Denise. A volatilidade eleitoral no estados: sistema partidário e democracia no Brasil. Rev Sociol. Polít., v. 17, n.33, p. 187-208, jun., 2009.Disponível em: www.scielo.br/pdf/rsocp/v17n33/v17n33a14.pdf. Acesso em: 2 de jan. 2013.

${ }^{17}$ A mobilização de informações tais como a avaliação dos governos pelos eleitores, além de detalhes sobre a formação das coligações, certamente permitiria conclusões mais categóricas, mas não é possível nos limites deste trabalho. Agradeço ao parecerista anônimo do Caderno CRH por apontar esta necessidade, que será atendida com o desenvolvimento da agenda de pesquisa.
BRAGA, Maria do S. S. O processo partidário-eleitoral brasileiro: padrões de competição política (1982-2002). São Paulo: Humanitas, 2006.

BRASIL,Tribunal Superior Eleitoral. Eleições anteriores. Brasília, 2010. Disponível em www.tse.gov.br. Acesso em 08/09/2010, 18:42:55.

DAHL, Robert. Political oppositions in western democracies. New Haven: Yale University Press, 1966

Polyarchy: participation and opposition. New Haven: Yale University Press, 1971.

GERRING, John. Social science methodology: a criterial framework. Cambridge: Cambridge University Press, 2001.

HANNEMAN, Robert A. ;MARK, Riddle. Introduction to social network methods. Riverside, University of California, 2005

HUNTINGTON, Samuel P. A terceira onda: a democratização no final do século XX. São Paulo: Atica, 1994.

INÁCIO, Magna (Coord.) O lugar das oposições na política subnacional:. projeto de cooperação acadêmica. Belo Horizonte, UFMG, 2008.

Oposições parlamentares nos legislativos estaduais. In: ENCONTRO ANUAL DA ANPOCS, 35. Caxambu, 2011. Anais... Caxambu: Associação Nacional de Pós-Graduação e Pesquisaem Ciências Sociais, 2011.

KINGDON, John. Agendas, alternatives, and public policies. New York: Longman, 2003.

LAAKSO, Markku; TAAGEPERA, Rein. "Effective” number of parties: a measure with application to West Europe. Comparative Political Studies, v. 12, n.1, p. 3-27, abr.,1979. Disponível em: www.pratiquesciencessociales.net/exposes/ S12.\%20The\%20Effective\%20Number\%20of\%20Parties\% 20A\%20Measure\%20with\%20Application\%20to\%20West\% 20Europe\%20(Laakso\%201979).pdf. Acesso em: 2 jan. 2013.

MAINWARINGS, Scott. Electoral volatility in Brazil. Party Politics, v. 4, n. 4, p. 523-545, out., 1998.

MÜLLER, Wolfgang C.; STROM, Kaare. Policy, office, or votes? how political parties in Western Europe make hard decisions. New York: Cambridge University Press, 1999.

NICOLAU, Jairo M. Sistemas eleitorais. Rio de Janeiro: Ed. FGV, 2004.

PEDERSEN, Mogens. On measuring party system change: a methodological critique and a suggestion. Comparative Political Studies, v. 12, n. 4, p. 387-403, jan.,1980.

PERES, Paulo S. Sistema partidário e dinâmica democrática no Brasil. 2005. 223f. Tese (Doutorado em Ciência Política) - Departamento de Ciência Política, Universidade de São Paulo, 2005.

POWER, Timothy J. Brazilian politicians and neoliberalism: mapping support for the cardoso Reforms, 1995-199. Journal of Interamerican Studies and World Affairs, Malden, v. 40 n. 4, p. 51-72, jul., 1998.

POWER, Timothy; ZUCCO JUNIOR, Cezar. (Org.) O congresso por ele mesmo: autopercepções da classe política brasileira. Belo Horizonte: UFMG, 2011.

TAROUCO, Gabriela. Brazilian parties according to their manifestos: political identity and programmatic emphases. Brazilian Political Science Review, São Paulo, v. 5, n. 1, 5476, 2011.Disponível em: http://bpsr.org.br/english/arquivos/ BPSR_v5_n1_artigos/Article_Gabriela.pdf. Acesso em: 3 jan. 2013.

Institucionalização partidária no Brasil (1982-2006) Revista Brasileira de Ciência Política, Brasília, n. 4, p. 169 186, jul./dez., 2010. Disponível em: http://seer.bce.unb.br/ index.php/rbcp/article/viewFile/6524/5265. Acesso em: 3 jan. 2013. 
OPPOSITION PARTIES IN FOUR STATES: the competitive environment in the electoral arena

\section{Gabriela Tarouco}

This article proposes an operationalization of the concept of opposition on the positions publically taken by the parties and tests their application in a comparative analysis of the electoral arena in four Brazilian states. The competitive atmosphere of situation versus opposition in the states of Minas Gerais, Pernambuco, São Paulo and Rio Grande do Sul is analyzed through a series of empirical indicators in the 2002 and 2006 elections. The analysis reveals large variations in oppositional competitiveness in coalition strategies and in voters' loyalty to their parties, even though the institutional effects did not vary. This kind of results suggests that specific local factors must be mobilized to explain the behavior of opposition parties at the subnational level.

KEY WORDS: oppositions, electoral competition, electoral arena, parties, subnational sphere.

\section{PARTIS D'OPPOSITION DANS LES ÉTATS:} l'ambiance de la compétition dans l'arèneélectorale

\section{Gabriela Tarouco}

Larticle propose une opérationnalisation du concept d'opposition fondé sur les positions assumées publiquement par les partis et vérifie son application dans une analyse comparée de l'arène électorale dans quatre états brésiliens. Le climat de compétition entre ceux qui assument le pouvoir et ceux qui s'y opposent dans les états de Minas Gerais, Pernambuco, Sao Paulo et Rio Grande do Sul est analysé à partir d'une série d'indicateurs empiriques au cours des élections de 2002 et de 2006. L'analyse présente de grandes variations au niveau de la compétitivité des oppositions, dans l'utilisation de stratégies de coalition et de loyauté des électeurs envers les partis, malgré l'invariabilité des effets institutionnels. Ces résultats suggèrent que des facteurs locaux spécifiques doivent être mis en œuvre pour expliquer le comportement des partis d'opposition à un niveau sous-national.

Mots-CLÉs: oppositions, compétition électorale, arène électorale, partis, sphère sous-nationale.

Gabriela da Silva Tarouco - Doutora em Ciência Política pelo IUPERJ. Professora do Departamento de Ciência Política da Universidade Federal de Pernambuco. Integra o Grupo de Pesquisa "Partidos, Eleições e Comportamento Político”, desenvolvendo pesquisas na área de Partidos Políticos e Governança Eleitoral. Suas mais recentes publicações são: "Brazilian Parties According to their Manifestos: Political Identity and Programmatic Emphases”, na Brazilian Political Science Review, v. 5, 2011 e "Institucionalização Partidária no Brasil (1982-2006)”, na Revista Brasileira de Ciência Política, v. 4, 2010. 
